\title{
Silica Sol-Gel Entrapment of the Enzyme Chloroperoxidase
}

\author{
Tuan Le, Selina Chan, Bassem Ebaid, and Monika Sommerhalter \\ Department of Chemistry and Biochemistry, California State University East Bay, 25800 Carlos Bee Boulevard, \\ Hayward, CA 94542, USA \\ Correspondence should be addressed to Monika Sommerhalter; monika.sommerhalter@csueastbay.edu
}

Received 3 June 2015; Revised 24 August 2015; Accepted 31 August 2015

Academic Editor: Jiazhi Yang

Copyright (C) 2015 Tuan Le et al. This is an open access article distributed under the Creative Commons Attribution License, which permits unrestricted use, distribution, and reproduction in any medium, provided the original work is properly cited.

\begin{abstract}
The enzyme chloroperoxidase (CPO) was immobilized in silica sol-gel beads prepared from tetramethoxysilane. The average pore diameter of the silica host structure $(\sim 3 \mathrm{~nm})$ was smaller than the globular CPO diameter $(\sim 6 \mathrm{~nm})$ and the enzyme remained entrapped after sol-gel maturation. The catalytic performance of the entrapped enzyme was assessed via the pyrogallol peroxidation reaction. Sol-gel beads loaded with $4 \mu \mathrm{g}$ CPO per $\mathrm{mL}$ sol solution reached 9-12\% relative activity compared to free CPO in solution. Enzyme kinetic analysis revealed a decrease in $k_{\text {cat }}$ but no changes in $K_{M}$ or $K_{I}$. Product release or enzyme damage might thus limit catalytic performance. Yet circular dichroism and visible absorption spectra of transparent CPO sol-gel sheets did not indicate enzyme damage. Activity decline due to methanol exposure was shown to be reversible in solution. To improve catalytic performance the sol-gel protocol was modified. The incorporation of 5, 20, or $40 \%$ methyltrimethoxysilane resulted in more brittle sol-gel beads but the catalytic performance increased to $14 \%$ relative to free $\mathrm{CPO}$ in solution. The use of more acidic casting buffers ( $\mathrm{pH} 4.5$ or 5.5 instead of 6.5 ) resulted in a more porous silica host reaching up to $18 \%$ relative activity.
\end{abstract}

\section{Introduction}

Silica nanostructures can be fabricated using a room temperature sol-gel process that is compatible with biomolecules $[1,2]$. The entrapment of enzymes inside these silica nanostructures has facilitated diverse applications in biocatalysis and biosensing [3]. Here, we demonstrate the use of sol-gel technology to make a biocatalyst based on entrapment of the enzyme chloroperoxidase (CPO) inside a silica nanostructure.

CPO (EC 1.11.1.10) is one of the most versatile heme enzymes known to date. It can be obtained as a secreted, glycosylated protein from the marine fungus Caldariomyces fumago $[4,5]$. CPO catalyzes halogenation, sulfoxidation, hydroxylation, and epoxidation reactions with high substrate promiscuity under environmentally benign conditions [6]. CPO catalyzed oxidative transformations are based on hydrogen peroxide or an alkyl peroxide as oxidant, whereas the equivalent traditional chemical reactions require stoichiometric amounts of heavy metal salts [7]. Another advantageous feature of $\mathrm{CPO}$ is its ability to perform these reactions in a highly enantioselective manner [8]. Transforming CPO into a practical biocatalyst for oxidative transformations in biosynthetic chemistry is therefore highly desirable. Further possible biotechnological applications of CPO include wastewater treatment or upgrading petroleum products [911]. The use of $\mathrm{CPO}$ as biocatalyst, however, is hampered by its loss of activity in the presence of organic solvents, deactivation at high concentrations of the oxidant $\mathrm{H}_{2} \mathrm{O}_{2}$, and instability at elevated temperatures $[8,12]$.

Various approaches have been attempted to improve the stability and productivity of $\mathrm{CPO}$ in solution [13-16] as well as in immobilized form [12, 17-21]. In our study, CPO was entrapped in a hydrogel prepared from the precursor tetramethoxysilane (TMOS) with or without the addition of methyltrimethoxysilane (MTMS). Enzyme immobilization offers key advantages, most notably ease of enzyme recovery and reusability [22]. Silica-based sol-gels furnish chemically inert and optically transparent immobilization matrices [2, 23]. However, sol-gel immobilization is often accompanied by a loss of enzymatic activity. This loss can be due to enzyme damage, leakage of enzyme from the immobilization host, or limited material transport of substrates and products within the sol-gel nanostructure. We examined each of these possible reasons using absorption and circular dichroism spectroscopy, porosimetry, and an enzyme activity assay for CPO, 
that is, the peroxidation of pyrogallol. The effect of methanol on CPO was also investigated since methanol is released from the precursor TMOS during the hydrolysis and condensation reactions of the sol-gel process. In our attempts to optimize the catalytic performance of sol-gel immobilized CPO, we exploited the stability of CPO in acidic solutions [24] and deviated from the $\mathrm{pH}$ range of $6.0-7.0$ which is typically employed in protein sol-gel immobilization procedures. The use of more acidic solutions in the sol-gel process might also be beneficial for various sol-gel applications based on other proteins that either withstand or thrive in acidic conditions.

\section{Materials and Methods}

2.1. Materials. CPO from C. fumago was purchased from Sigma-Aldrich. The turbid suspensions were centrifuged at 15,000 rpm for 5 minutes in an Eppendorf microcentrifuge. The concentrations of the CPO supernatants were determined via the intensity of the Soret band [25] and confirmed with protein assays [26]. The CPO samples used in this study had concentrations in the range of 9 to $15 \mathrm{mg} / \mathrm{mL}$. All other reagents were purchased from Sigma-Aldrich or Fisher Scientific. Aqueous solutions were prepared with deionized water obtained from a Millipore Milli-Q device.

2.2. Sol-Gel Entrapment. A sol solution was prepared by mixing $50 \mu \mathrm{L}$ deionized water, $4.7 \mu \mathrm{L} 0.010 \mathrm{M}$ hydrochloric acid, and $235 \mu \mathrm{L}$ TMOS in a microcentrifuge tube. If MTMS was included, TMOS and MTMS were premixed. The molar ratio of MTMS was either 5, 20, or 40\% of the total MTMS and TMOS precursor mixture. The sol solution was sonicated in a Branson 1510 sonicator bath filled with ice water for 30 minutes and either used immediately thereafter or stored for up to a week at $4^{\circ} \mathrm{C}$. In a microcentrifuge tube, $140 \mu \mathrm{L}$ sol, $480 \mu \mathrm{L}$ casting buffer, and $500 \mu \mathrm{L}$ diluted CPO solution were mixed. The casting buffers were prepared by mixing $0.1 \mathrm{M}$ citric acid and $0.2 \mathrm{M}$ dibasic sodium phosphate to reach $\mathrm{pH}$ values of $4.5,5.5,6.0$, or 6.5 . CPO was diluted in $20 \mathrm{mM}$ potassium phosphate-potassium hydroxide buffer, $\mathrm{pH}$ 6.0. Small beads of $50 \mu \mathrm{L}$ volume were prepared by pipetting the mixture onto parafilm sheets. As the $\mathrm{pH}$ value of the casting buffer decreased the gelation time increased from approximately 15 minutes ( $\mathrm{pH}$ 6.5) to $240 \mathrm{~min}$ ( $\mathrm{pH} \mathrm{4.5).} \mathrm{The} \mathrm{CPO} \mathrm{sol-gel} \mathrm{beads}$ were transferred into glass tubes in sets of three to eight beads and covered with a storage buffer composed of $2.1 \mathrm{~mL}$ deionized water and $0.32 \mathrm{~mL} 0.1 \mathrm{M}$ citric acid- $0.2 \mathrm{M}$ dibasic sodium phosphate buffer, $\mathrm{pH}$ 4.2. This storage buffer was typically exchanged with a new portion of storage buffer after one hour, and thereafter each day for seven or ten days. The storage temperature was $4^{\circ} \mathrm{C}$.

2.3. Activity Assays. Activity assays were typically conducted in $0.1 \mathrm{M}$ citric acid- $0.2 \mathrm{M}$ dibasic sodium phosphate buffer, $\mathrm{pH} 4.2$ with 2.7 or $8.6 \mathrm{mM} \mathrm{H}_{2} \mathrm{O}_{2}, 35 \mathrm{mM}$ pyrogallol, and $0.2 \mu \mathrm{g} / \mathrm{mL}$ CPO. CPO was added last to start the reaction. The assay volume was $3 \mathrm{~mL}$. Control reactions without the enzyme were performed in parallel. The hydrogen peroxide and pyrogallol solutions were prepared fresh on the day of the measurements and pyrogallol was kept in the dark.
The absorbance increase at $420 \mathrm{~nm}$ was monitored every 3 seconds for 2 minutes using a NanoDrop 2000c (Thermo Fisher Scientific) with cuvette option. A molar absorptivity value of $2640 \mathrm{M}^{-1} \mathrm{~cm}^{-1}$ for the product purpurogallin was used to calculate the enzyme activity [24]. One International Unit (IU) corresponds to the formation of one micromole purpurogallin in one minute at room temperature and $\mathrm{pH} 4.2$.

For enzyme kinetic studies, the concentrations of the substrates pyrogallol and $\mathrm{H}_{2} \mathrm{O}_{2}$ were varied. The substrate inhibition model described by (1) was used to fit the dependence of the initial reaction velocity, $v_{0}$, on the substrate concentration, $[S]$. The fit parameters are the MichaelisMenten constant, $K_{M}$, the substrate inhibition constant, $K_{I}$, and the maximum initial reaction velocity, $v_{\max }$. The parameter $v_{\max }$ depends on the turnover number, $k_{\mathrm{cat}}$, and the enzyme concentration, $[E]$. The fit was carried out with the program EnzFitter from Biosoft:

$$
v_{0}=\frac{v_{\max } \cdot[S]}{K_{M}+[S]+[S]^{2} / K_{I}} \quad \text { with } v_{\max }=k_{\text {cat }} \cdot[E] .
$$

To detect how much CPO leaked from sol-gel beads, activity assays were conducted with the storage buffers that were removed and replaced during the maturation phase of the sol-gel beads. These assays were conducted in a similar manner as described above with the following exception: the assay was started with the addition of $\mathrm{H}_{2} \mathrm{O}_{2}$ as no extra CPO was added.

Activity assays with CPO sol-gel beads were performed with longer time intervals of 20 or 30 seconds for a total duration of 5 minutes. A Milton Roy Spectronic 20D instrument was used to monitor the absorbance at $420 \mathrm{~nm}$. Agitation of the reaction solution and the CPO sol-gel beads via inversion or pipetting was crucial to ensure good mixing in between absorbance recordings. Control reactions with sol-gel beads that did not contain CPO confirmed that the sol-gel beads themselves do not catalyze the peroxidation of pyrogallol.

2.4. Spectroscopic Studies (CD and UV/VIS). CD spectra were recorded with an AVIV Model 215 circular dichroism spectrometer at $25^{\circ} \mathrm{C}$. The temperature was controlled with a thermostat. We employed the sample preparation method developed by Eggers and Valentine [27]. A buffer of low concentration ( $2 \mathrm{mM}$ sodium phosphate, $\mathrm{pH} 7.0$ ) was chosen to minimize total sample absorbance in the UV region. To achieve efficient gelation despite the low concentration of the buffer, a $\mathrm{pH}$ value of 7.0 was selected. A sol solution was prepared

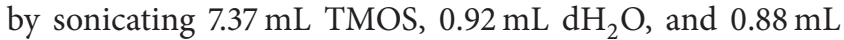
$0.01 \mathrm{M}$ hydrochloric acid for 20 minutes in an ice-water bath. A portion of $1.75 \mathrm{~mL}$ of this sol-gel solution was gently mixed with $2.625 \mathrm{~mL}$ CPO solution containing $12 \mu \mathrm{M}$ CPO in $2 \mathrm{mM}$ sodium phosphate, $\mathrm{pH} 7.0$, and cast into a plastic cassette of $1 \mathrm{~mm}$ thickness. The cassettes were purchased from Life Technologies. For the first four days, the storage buffer on top of the sol-gel sheet was exchanged daily. For complete maturation inside the more enclosed cassettes, the CPO solgel sheets were stored for one month at $4^{\circ} \mathrm{C}$. Prior to the actual CD measurements, the cassette housing the CPO sol-gel was opened. A small piece was cut out with a razor blade and 
transferred into a CD quartz cuvette of $2 \mathrm{~mm}$ thickness. The remaining space was filled with $2 \mathrm{mM}$ sodium phosphate buffer, $\mathrm{pH}$ 7.0.

UV/VIS spectra were recorded using a UV mini 1240 Shimadzu single beam spectrophotometer. The CPO sol-gel material was prepared as described in Section 2.2. However, instead of casting beads, the solution was poured into $1 \mathrm{~mm}$ thick plastic cassettes and a higher $\mathrm{CPO}$ concentration yielding $1.6 \mathrm{mg} / \mathrm{mL} \mathrm{CPO} \mathrm{in} \mathrm{the} \mathrm{final} \mathrm{sol-gel} \mathrm{sheet} \mathrm{was} \mathrm{used.} \mathrm{The}$ CPO sol-gel sheet was stored in the cassette for one month at $4^{\circ} \mathrm{C}$. A rectangular piece was cut out and placed onto one wall of a plastic cuvette of $10 \mathrm{~mm}$ thickness. The CPO sol-gel sheet remained attached to the plastic wall after the cuvette was filled with $50 \mathrm{mM}$ potassium phosphate buffer, $\mathrm{pH}$ 6.0. To test the effect of changing the $\mathrm{pH}$ value of buffers surrounding the $\mathrm{CPO}$ sol-gel sheets, the molarity of the potassium phosphate buffers at various $\mathrm{pH}$ values was increased to $0.5 \mathrm{M}$.

2.5. Influence of Methanol on CPO's Catalytic Activity and Spectroscopic Properties. CPO dissolved at concentrations of up to $9 \mu \mathrm{M}$ in $0.1 \mathrm{M}$ citrate- $0.2 \mathrm{M}$ phosphate buffer, $\mathrm{pH} 4.2$ was incubated with $11 \% \mathrm{v} / \mathrm{v}$ methanol. After specific time intervals, sample aliquots were removed to record UV/VIS or $\mathrm{CD}$ spectra or to measure the enzymatic activity via the pyrogallol peroxidation assay. Reference samples without methanol were prepared in parallel. To test whether any effects caused by methanol exposure might be reversible methanol treated samples were dialyzed for three hours in a Pierce Slide-A-Lyzer (10,000 MWCO) against $1 \mathrm{~L}$ of $0.01 \mathrm{M}$ citrate-0.02 M phosphate buffer, $\mathrm{pH} 4.2$ at room temperature.

2.6. Porosimetry Measurements. All porosimetry measurements were conducted with an ASAP 2020 physisorption analyzer from Micromeritics using nitrogen gas. To prepare the samples, the solvent exchange procedure described by Harreld and coworkers was used [28]. The sol-gel beads (typically 8 ) were placed in $\sim 4 \mathrm{~mL}$ acetone overnight. The acetone was exchanged each day for three days. For the final two days, n-pentane was used instead of acetone. N-pentane and acetone are miscible with each other, but $\mathrm{n}$-pentane evaporates more readily than acetone. This technique yields dry beads while minimizing the risk of pore collapse. The beads were placed in the sample degas station of the physisorption analyzer for approximately 8 hours at $37^{\circ} \mathrm{C}$ until constant pressure was reached. Nitrogen adsorption and desorption curves were recorded and analyzed with the Brunauer-EmmettTeller (BET) algorithm. Proper performance of the instrument was confirmed with a silica-alumina standard provided by Micromeritics.

\section{Results and Discussion}

3.1. Peroxidation of Pyrogallol Catalyzed by Free and Sol-Gel Entrapped CPO. The catalytic activity of $\mathrm{CPO}$ was assessed by monitoring the peroxidation reaction of pyrogallol. To determine optimal reaction conditions, we varied the $\mathrm{pH}$ value of the assay buffer and the concentrations of pyrogallol and hydrogen peroxide. Our observations for free CPO agree well with previous studies [24, 29]. Acidic conditions, with
$\mathrm{pH}$ values in the range of 3.5 to 4.5 , and pyrogallol concentrations at approximately $35 \mathrm{mM}$ resulted in optimum catalytic performance. Very high pyrogallol concentrations gave rise to substrate inactivation, but the enzyme was even more sensitive towards inactivation by the cosubstrate $\mathrm{H}_{2} \mathrm{O}_{2}$. The $\mathrm{H}_{2} \mathrm{O}_{2}$ concentration should not exceed $10 \mathrm{mM}$. The enzyme kinetic data obtained for sol-gel entrapped CPO displayed similar features albeit at much lower specific activity. Notably, sol-gel entrapment did not abolish the detrimental effect of $\mathrm{H}_{2} \mathrm{O}_{2}$. All data displayed in Figure 1 was thus fitted with a substrate inhibition model (see (1)).

The enzyme kinetic parameters for the peroxidation of pyrogallol catalyzed by free and sol-gel entrapped CPO are summarized in Table 1 . Significantly smaller $v_{\max }$ and thus $k_{\text {cat }}$ values were obtained for sol-gel entrapped CPO compared to free CPO. The parameters $K_{m}$ and $K_{I}$ did not change significantly in response to sol-gel entrapment for either substrate. The poor quality of the fit shown in Figure 1(b) for the data on sol-gel entrapped CPO might be caused by large data point variations and the limitations of the substrate inhibition model. Manoj et al. [29] demonstrated that the substrate inhibition model used here (see (1)) can yield acceptable fits for individual substrate variations, but global fit parameters were shown to be unattainable [29]. For example, the $K_{M}$ and $K_{I}$ values of one substrate depended on the concentration of the other cosubstrate. All kinetic parameters determined here are thus only apparent values and the parameters for sol-gel entrapped CPO are further influenced by additional factors. For example, $k_{\text {cat }}$ was calculated based on the assumption that all entrapped $\mathrm{CPO}$ molecules are able to participate in the catalytic process. This will not be the case for $\mathrm{CPO}$ molecules that are entrapped in closed silica pores or are otherwise permanently shielded and for $\mathrm{CPO}$ molecules with compromised functionality due to enzyme damage. The decrease in $k_{\text {cat }}$ (and also $v_{\max }$ ) might thus signify an apparent decrease in accessible and/or active CPO molecules upon sol-gel entrapment. Notably, hindered product release can also cause a decrease in $k_{\text {cat. }}$. The $k_{\text {cat }}$ value is either determined by the rate of catalytic turnover or the rate of product release, depending on which of the two steps is slower and thus rate-limiting. The silica nanostructure does not seem to impose any significant diffusional constraints on the molecules pyrogallol and possibly $\mathrm{H}_{2} \mathrm{O}_{2}$. If these substrate molecules were encountering substantial diffusional barriers, an increase in their apparent $K_{M}$ and $K_{I}$ values would be expected.

\subsection{Entrapment and Catalytic Performance of CPO in Sol-Gel} Beads. To further assess the entrapment and catalytic performance of the immobilized enzyme, different amounts of CPO were immobilized inside sol-gel beads corresponding to final concentrations of $40 \mu \mathrm{g} / \mathrm{mL}, 8 \mu \mathrm{g} / \mathrm{mL}$, and $4 \mu \mathrm{g} / \mathrm{mL}$ per total sol-gel solution. The storage buffer was exchanged to remove methanol originating from the hydrolysis and condensation steps of the sol-gel formation. CPO activity was measured in these exchanged buffer samples and compared to a reference sample with free $\mathrm{CPO}$ in solution to quantify enzyme leakage (see Figure 2). Higher enzyme loading resulted in more 


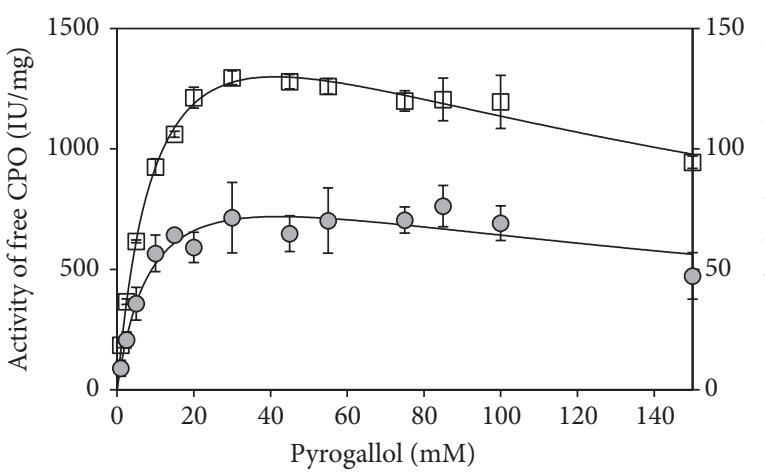

(a)

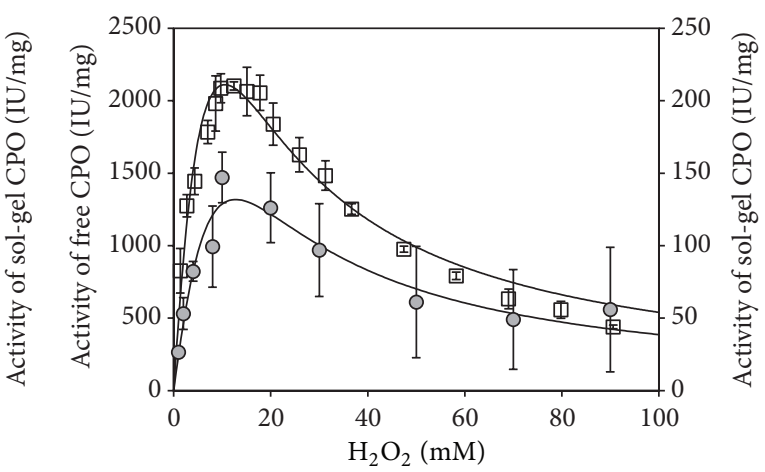

(b)

FIGURE 1: Peroxidation of pyrogallol catalyzed by free CPO (open squares; $0.575 \mu \mathrm{g}$ CPO in $3 \mathrm{~mL}$ total assay volume) and sol-gel entrapped CPO (grey circles; $0.575 \mu \mathrm{g}$ CPO entrapped in three sol-gel beads placed in $3 \mathrm{~mL}$ total assay volume). The CPO sol-gel beads were prepared from TMOS with a pH 6.0 casting buffer and matured for one week with a buffer exchange on every other day. The activity assays were performed in $0.1 \mathrm{M}$ citric acid- $0.2 \mathrm{M}$ dibasic sodium phosphate buffer, $\mathrm{pH} 4.2$ with constant concentrations of either $2.7 \mathrm{mM} \mathrm{H}_{2} \mathrm{O}_{2}$ (a) or $35 \mathrm{mM}$ pyrogallol (b). All data were measured in triplicate and are displayed as mean values \pm one standard deviation. The parameters of the curve fits are summarized in Table 1.

TABLE 1: Enzyme kinetic parameters for the CPO catalyzed peroxidation of pyrogallol ${ }^{*}$

\begin{tabular}{|c|c|c|c|c|}
\hline & $K_{M}(\mathrm{mM})$ & $K_{I}(\mathrm{mM})$ & $v_{\max }(\mathrm{IU} / \mathrm{mg})$ & $k_{\text {cat }}(1 / \mathrm{sec})$ \\
\hline \multicolumn{5}{|l|}{ Pyrogallol } \\
\hline Free CPO $\left(R^{2}=0.983\right)$ & $11 \pm 1.0$ & $160 \pm 20$ & $2000 \pm 80$ & $1400 \pm 60$ \\
\hline Sol-gel entrapped CPO $\left(R^{2}=0.847\right)$ & $9.3 \pm 2.6$ & $190 \pm 74$ & $100 \pm 12$ & $70 \pm 8.4$ \\
\hline \multicolumn{5}{|l|}{$\mathrm{H}_{2} \mathrm{O}_{2}$} \\
\hline Free CPO $\left(R^{2}=0.921\right)$ & $17 \pm 6.2$ & $6.4 \pm 2.2$ & $9100 \pm 2500$ & $6370 \pm 1750$ \\
\hline Sol-gel entrapped CPO $\left(R^{2}=0.657\right)$ & $27 \pm 39$ & $6.1 \pm 8.6$ & $680 \pm 830$ & $480 \pm 580$ \\
\hline
\end{tabular}

${ }^{*}$ Enzyme kinetic parameters were obtained by fitting the data shown in Figure 1(a) (pyrogallol) and Figure $1(\mathrm{~b})\left(\mathrm{H}_{2} \mathrm{O}_{2}\right)$ to a substrate inhibition model (see (1)). All parameters are presented as value of the fit \pm one standard error of the fit.

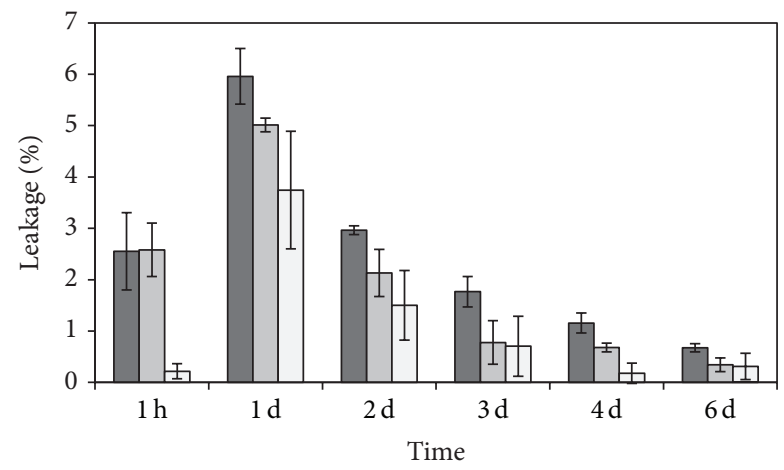

FIGURE 2: Three sets of CPO sol-gel beads with CPO concentrations of $40 \mu \mathrm{g} / \mathrm{mL}$ (dark grey bars), $8 \mu \mathrm{g} / \mathrm{mL}$ (grey bars), and $4 \mu \mathrm{g} / \mathrm{mL}$ (light grey bars) were aged for one week. The storage buffer was replaced in the time intervals indicated on the graph and tested for CPO leakage. Each set was replicated three times and contained three beads per sample tube. The specific activity of the reference sample with free CPO in solution was $1436 \pm 39 \mathrm{IU} / \mathrm{mg}$. The column heights represent the mean value and the error bars represent \pm one standard deviation.

enzyme leakage. As the sol-gel material matured and more connections formed within the silica mesh, enzyme leakage declined.
Table 2 contains the results of the activity measurements with the CPO sol-gel beads and summarizes the cumulative leakage over the first six days. The activity measurements were performed with CPO sol-gel beads that were seven days old. Each assay comprised $0.1 \mathrm{M}$ citric acid- $0.2 \mathrm{M}$ dibasic sodium phosphate buffer, $\mathrm{pH} 4.2,2.7 \mathrm{mM} \mathrm{H}_{2} \mathrm{O}_{2}$, and $35 \mathrm{mM}$ pyrogallol. The CPO sol-gel beads with the highest $\mathrm{CPO}$ loading of $40 \mu \mathrm{g}$ CPO per $\mathrm{mL}$ sol-gel yielded the highest absolute activity values of $249 \pm 33 \mathrm{mIU}$. A comparison among specific activity values reported per $\mathrm{mg}$ of initially loaded CPO, however, clearly showed that the CPO sol-gel beads with a lower enzyme content of 8 or $4 \mu \mathrm{g} / \mathrm{mL}$ performed better. At a higher loading of CPO, more CPO molecules might be obstructed by either other enzyme molecules or the silica nanostructure. Also, some of these CPO molecules might be entrapped in closed pores.

Another set of three tubes each containing three beads loaded with $4 \mu \mathrm{g} / \mathrm{mL}$ CPO was aged for one week and tested for reusability (see Figure 3). The CPO sol-gel beads can be reused up to three times in a convenient manner by replacing the liquid phase composed of buffer and product molecules with new buffer and substrate. However, a further decline in catalytic performance was apparent. We also noticed that all CPO sol-gel beads adopted the yellow-orange color of the product purpurogallin after the first use. Gentle washing with 
TABLE 2: Catalytic performance of sol-gel beads loaded with different CPO amounts.

\begin{tabular}{|c|c|c|c|}
\hline CPO loading of sol-gel beads $(\mu \mathrm{g} / \mathrm{mL})$ & 40 & 8 & 4 \\
\hline Activity $(\mathrm{mIU})^{*}$ & $249 \pm 33$ & $138 \pm 18$ & $76 \pm 4$ \\
\hline Specific activity (IU/mg) ${ }^{*}$ & $41 \pm 6$ & $115 \pm 15$ & $127 \pm 6$ \\
\hline Relative activity compared to free $\mathrm{CPO}(\%)^{\#}$ & 2.9 & 8.0 & 8.80 \\
\hline Cumulative leakage for six days $(\%)^{\dagger}$ & 15 & 12 & 7 \\
\hline
\end{tabular}

${ }^{*}$ Absolute activity values in mIU $\left(\times 10^{-3}\right.$ International Units $)$ and specific activity values per mg initially loaded CPO are presented as mean values \pm one standard deviation. All sample sets were prepared in triplicate. ${ }^{\#}$ The relative activity was based on a reference assay with free CPO in solution. The reference value was $1436 \pm 39 \mathrm{IU} / \mathrm{mg} .{ }^{\dagger}$ The cumulative leakage over six days of maturation corresponds to the summation of the leakage data shown in Figure 2 .

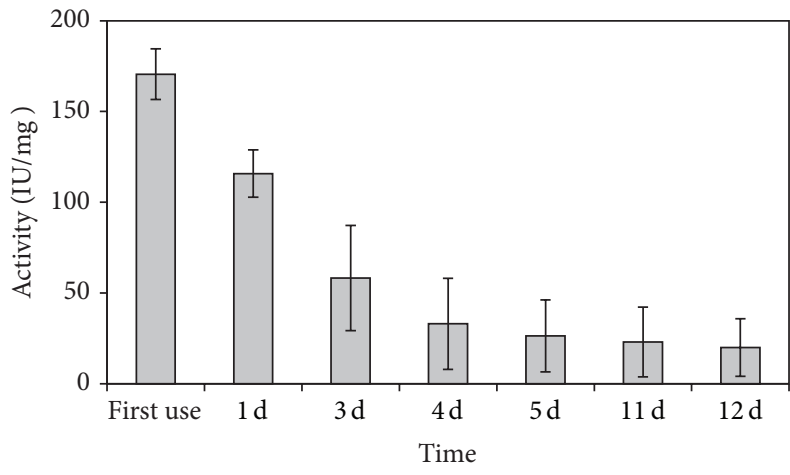

FIGURE 3: Reusability test for CPO sol-gel beads loaded with $4 \mu \mathrm{g} / \mathrm{mL}$ CPO. Three sets, each with three beads per tube, were used in this test. The column heights represent the mean specific activity value and the error bars represent \pm one standard deviation. The first measurement was taken after the beads were aged for one week with daily buffer exchanges. The number of days that passed before the next reuse is listed on the $x$-axis.

the storage buffer diminished the coloration only slightly. Thus, clogging of the sol-gel nanostructure with product molecules was one factor that hampered the reusability of the $\mathrm{CPO}$ sol-gel beads. Furthermore, the peroxidation reactions catalyzed by $\mathrm{CPO}$ are prone to substrate inhibition (see Figure 1). Trapped pyrogallol and $\mathrm{H}_{2} \mathrm{O}_{2}$ molecules could therefore interfere with effective reuse. Jung and Hartmann demonstrated that in situ generation of hydrogen peroxide via coimmobilization of glucose oxidase can improve the reusability of cross-linked $\mathrm{CPO}$ molecules entrapped in mesoporous molecular sieves [30].

The specific activity of three independently prepared sets of sol-gel beads all containing $\sim 4 \mu \mathrm{g} / \mathrm{mL}$ CPO was different: $70 \pm 15 \mathrm{IU} / \mathrm{mg}$ (Figure 1), $127 \pm 6 \mathrm{IU} / \mathrm{mg}$ (Table 2), and $171 \pm 14 \mathrm{IU} / \mathrm{mg}$ (Figure 3). The CPO sol-gel materials used for generating the data presented in Table 2 and Figure 3 were prepared from the same $\mathrm{CPO}$ vial with a free $\mathrm{CPO}$ reference value of $1436 \pm 39 \mathrm{IU} / \mathrm{mg}$. The reference value for the first CPO vial was only $1280 \pm 80 \mathrm{IU} / \mathrm{mg}$. However, many other experimental parameters, such as the exact sol-gel composition, the quality of all starting materials, humidity, temperature, and duration of sol-gel drying phase, can also influence the properties of the final sol-gel material. Therefore, all CPO sol-gel beads that are compared within one table or graph were prepared on the same day with the same reagent batches in parallel.
3.3. Modification of Sol-Gel Procedure with respect to Methanol Release. Next, we tested whether minor modifications in the sol-gel procedure that influence the retention of methanol released from the sol-gel precursor TMOS would result in any significant changes. On the same day, three different sets of CPO sol-gel beads all containing $4 \mu \mathrm{g} / \mathrm{mL} \mathrm{CPO} \mathrm{were}$ prepared in triplicate. The first set was prepared with a procedure that facilitates methanol release by using an open vessel while sonicating the sol solution and performing daily buffer exchanges during the first week of sol-gel maturation. The second and third sets were prepared using a closed sonication vessel and no buffer exchange was performed for the third set. Despite these modifications, all three sets prepared on the same day yielded virtually identical specific activity values of $167 \pm 18 \mathrm{IU} / \mathrm{mg}, 164 \pm 10 \mathrm{IU} / \mathrm{mg}$, and $178 \pm 21 \mathrm{IU} / \mathrm{mg}$, respectively. A more vigorous procedure presented by Ferrer et al. [31] involves rotavaporization of the sol solution prior to addition of the buffered enzyme solution. In our laboratory, this method was not successful as sol solidification started to set in too rapidly to achieve consistent gelation.

Overall, the catalytic performance of the best set of solgel beads was only $12.5 \pm 1.5 \%$ in comparison to the reference assay with free CPO in solution. Possible reasons for the decline in catalytic performance upon entrapment include (1) loss of enzyme due to leakage from the sol-gel matrix, (2) damage to the enzyme caused by the entrapment procedure, or (3) hindered substrate or product diffusion within the solgel nanostructure. As mentioned above, enzyme leakage did occur, but it can only account for a small loss of approximately $10 \%$. In the experiments described below, we tested for the two remaining possible reasons for the decline in catalytic performance of the sol-gel entrapped CPO and also examined the effect of methanol on CPO.

\subsection{CD and UV/VIS Spectroscopy with Sol-Gel Entrapped} $\mathrm{CPO}$. To monitor possible enzyme damage, we exploited the fact that sol-gels prepared from TMOS are transparent. Circular dichroism and visible absorbance spectra of free $\mathrm{CPO}$ in solution and $\mathrm{CPO}$ in sol-gel entrapped form are shown in Figures 4 and 5, respectively. The spectra of free CPO and sol-gel entrapped CPO are virtually identical to each other. Minor changes in intensity of the spectroscopic signals are most likely due to scattering effects from the sol-gel surface or the shrinkage of the sol-gel material during the maturation process. Shrinkage slightly raises the concentration of the sample but also decreases the spectroscopic path length. The $\mathrm{CD}$ spectra are typical for a protein with high alpha helical 


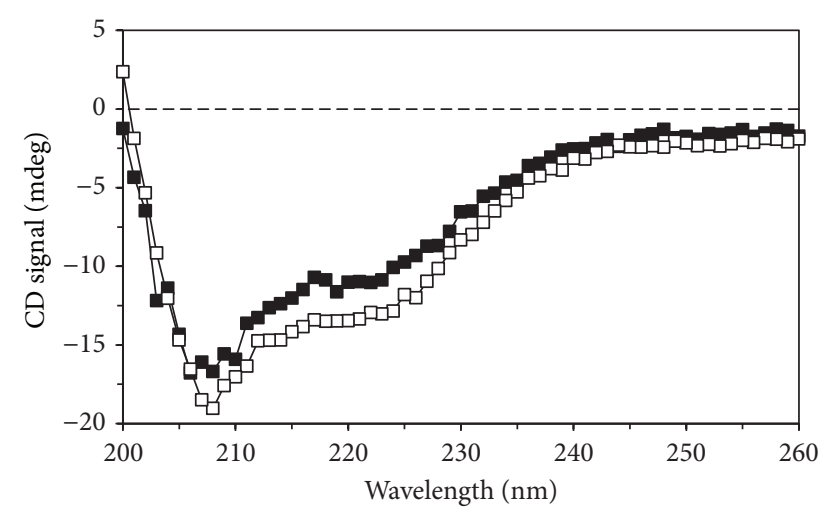

FIGURE 4: CD spectra of sol-gel entrapped CPO (black squares) and free CPO (white squares). The CPO concentration was $7 \mu \mathrm{M}$ in the silica sol-gel sheet of $\sim 1 \mathrm{~mm}$ thickness. The solution sample containing $7 \mu \mathrm{M}$ CPO in $2 \mathrm{mM}$ sodium phosphate buffer, $\mathrm{pH} 7.0$, was measured in a cuvette of $1 \mathrm{~mm}$ path length.

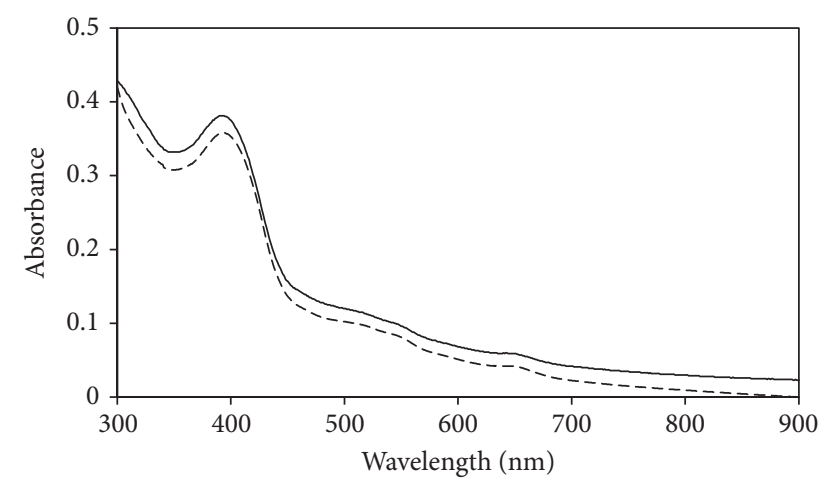

Figure 5: Absorbance spectra of sol-gel entrapped CPO (solid line) and free CPO (dashed line). The silica sol-gel sheet was $\sim 1 \mathrm{~mm}$ thick and contained $1.6 \mathrm{mg} / \mathrm{mL}$ CPO. The sheet was placed on the wall of a $10 \mathrm{~mm}$ wide plastic cuvette and immersed in $50 \mathrm{mM}$ potassium phosphate buffer, $\mathrm{pH}$ 6.0. The solution reference sample was prepared from the same CPO stock via dilution to $0.16 \mathrm{mg} / \mathrm{mL}$ $(4 \mu \mathrm{M})$ with $50 \mathrm{mM}$ potassium phosphate buffer, pH 6.0 in a $10 \mathrm{~mm}$ thick plastic cuvette.

content. This finding agrees with the $\mathrm{X}$-ray protein structure of $\mathrm{CPO}[32]$ and previously determined $\mathrm{CD}$ data $[15,33]$.

The visible absorbance spectra shown in Figure 5 are typical for the active form of $\mathrm{CPO}$ with a five-coordinate iron center in the heme chromophore [34]. As the $\mathrm{pH}$ value increases above $\mathrm{pH} 7.0, \mathrm{CPO}$ is inactivated, the iron center in the heme group becomes six-coordinate, and the Soret band shifts to a longer wavelength [34]. This spectroscopic transition can also be observed in CPO sol-gel sheets despite the entrapment of the enzyme inside the silica matrix. Figure 6 displays the absorption spectra of CPO sol-gel sheets immersed in $0.5 \mathrm{M}$ phosphate buffers at $\mathrm{pH}$ values of $6.0,8.0$, and 10.0. In comparison to solution spectra, more alkaline conditions are necessary to achieve the Soret peak characteristic for sixfold coordinated heme iron centers. It is conceivable that the silanol groups in the sol-gel impose an additional buffering effect. According to Dunn and Zink [35],

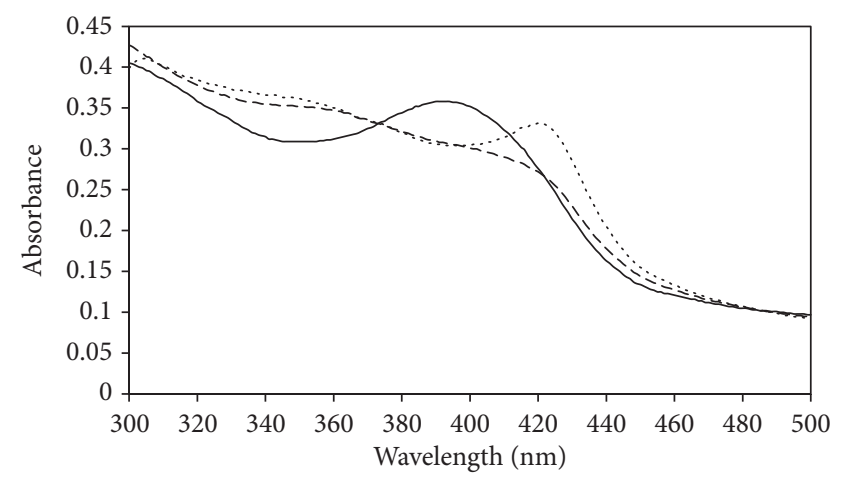

FIGURE 6: Absorbance spectra of sol-gel entrapped CPO immersed in $0.5 \mathrm{M}$ potassium phosphate buffer with $\mathrm{pH}$ values of 6.0 (solid line), 8.0 (dashed line), and 10.0 (dotted line). The silica sol-gel sheets of $1 \mathrm{~mm}$ thickness loaded with $1.6 \mathrm{mg} / \mathrm{mL}$ CPO were placed on the wall of plastic cuvette with a path length of $10 \mathrm{~mm}$.

the $\mathrm{pH}$ can be up to one $\mathrm{pH}$ unit lower inside a sol-gel pore than in the surrounding aqueous buffer.

The low apparent $k_{\text {cat }}$ values for sol-gel entrapped CPO (see Table 1) indicate that a significant number of entrapped $\mathrm{CPO}$ molecules were unable to catalyze the peroxidation of pyrogallol in an effective manner. CD and visible absorption spectra, however, did not indicate any enzyme damage. It should be noted that both spectroscopic methods can only address specific features of the enzyme. These features are the overall secondary structure of the protein, the electronic configuration of the active site chromophore, and the ability to rearrange the coordination sphere of the heme iron center in response to an external change in $\mathrm{pH}$ value.

3.5. Influence of Methanol on the Spectroscopic Features and Activity of Free CPO. Methanol is released from the sol-gel precursor TMOS. If we assume complete hydrolysis of TMOS and no evaporation of methanol, the protein is exposed to a methanol concentration of $11 \% \mathrm{v} / \mathrm{v}$ as the buffered enzyme solution and the sol are mixed and pipetted onto the parafilm for gelation and drying. The transfer into storage buffer and the subsequent exchange of buffer drastically lower the methanol content during the maturation phase of the sol-gel. After the first buffer exchange, the methanol concentration is only $0.03 \% \mathrm{v} / \mathrm{v}$.

To study the influence of methanol on the spectroscopic features of CPO, the enzyme was incubated with $11 \% \mathrm{v} / \mathrm{v}$ methanol and UV/VIS and CD spectra were recorded. We did not detect a change in the spectroscopic features of the CD spectra after several hours of incubation (data not shown), but methanol exposure did have a small and immediate effect on UV/VIS absorption spectra (see Figure 7). The absorption maximum of the Soret band shifted from $396 \mathrm{~nm}$ to $400 \mathrm{~nm}$. Notably, this shift was reversible via dialysis. The methanol removal caused a 1.3 -fold increase in sample volume. We adjusted the corresponding spectroscopic trace in Figure 7 for this dilution effect. 


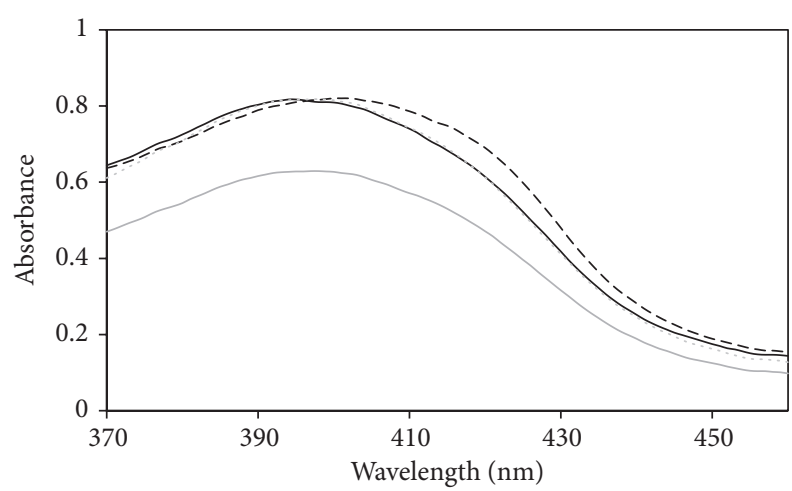

FIGURE 7: Absorption spectra of $9 \mu \mathrm{M}$ CPO in $0.1 \mathrm{M}$ citrate- $0.2 \mathrm{M}$ phosphate buffer, $\mathrm{pH} 4.2$ (solid line), in $11 \% \mathrm{v} / \mathrm{v}$ methanol and $0.1 \mathrm{M}$ citrate-0.2 M phosphate buffer, $\mathrm{pH} 4.2$ (dashed line), dialyzed sample (grey solid line), and dialyzed sample adjusted for 1.3-fold volume increase (grey dotted line).

In agreement with previous studies [36], we observed a drastic decline in CPO's catalytic performance after incubation of CPO with organic solvents. Compared to an aqueous reference sample without methanol, only $57 \%$ residual activity was detected after incubation with $11 \% \mathrm{v} / \mathrm{v}$ methanol for 2 hours. After one day, the residual activity still remained at $57 \%$. We further discovered that the detrimental effect of methanol was reversible. Up to $96 \%$ of the sample's initial activity was recovered after dialysis. Sample dilution also resulted in the enzyme's recovery. Decreasing the methanol content to $5 \%$ or $1 \% \mathrm{v} / \mathrm{v}$ via sample dilution resulted in $90 \%$ and $100 \%$ relative activity in comparison to identically diluted samples from the same CPO batch that were not exposed to methanol. Our finding that damage caused by methanol was reversible in solution has implications for other studies on the use of CPO in organic solvents or in biphasic solvent systems $[36,37]$. Several CPO substrates which can be converted into products of industrial interest have high solubility in nonpolar organic solvents [8].

Also, if any initial damage caused by methanol exposure was also reversible for sol-gel entrapped $\mathrm{CPO}$, immediate reduction in methanol content via evaporation of methanol from the sol solution or daily buffer exchanges during the gel maturation phase would not critically alter the final performance of the CPO sol-gel beads. This might explain why the three different, but parallel, preparations outlined in Section 3.3 resulted in virtually identical performance for the three different CPO sol-gel bead sets. On the other hand, manifestation of unrecoverable enzyme damage would explain the low apparent $k_{\text {cat }}$ values determined for sol-gel entrapped CPO (see Table 1). It is conceivable that recovery from damage caused by methanol exposure is less effective for CPO molecules entrapped within the silica sol-gel host compared to free $\mathrm{CPO}$ in solution.

3.6. Hindered Material Transport in CPO Sol-Gel Beads. After their first use, all CPO sol-gel beads adopted a persistent yellow coloration indicating the entrapment of the product purpurogallin. Attractive intermolecular forces and physical constraints both can delay the release of product molecules from the silica nanostructure. If product release becomes rate-limiting, the apparent $k_{\text {cat }}$ value decreases as observed in the enzyme kinetic analysis. Hindered substrate diffusion, however, was not supported by enzyme kinetic experiments as the $K_{M}$ and $K_{I}$ values for the main substrate pyrogallol were virtually identical for sol-gel entrapped and free CPO (see Table 1). We cannot explain why pyrogallol and purpurogallin would show different material transport properties inside the silica nanostructure. Both molecules have similar functional groups and purpurogallin (MW $220 \mathrm{~g} / \mathrm{mol}$ ) is only somewhat larger than pyrogallol (MW $116 \mathrm{~g} / \mathrm{mol}$ ). An alternative explanation would involve side-reactions forming alternate charged products or the trapping of reactive, colored intermediates.

The alternative peroxidation substrate $2,2^{\prime}$-azino-bis(3ethylbenzothiazoline-6-sulfonic acid) (ABTS) is particularly large (MW $515 \mathrm{~g} / \mathrm{mol}$ ) and the product of the peroxidation reaction carries a positive charge [24]. Deprotonated silanol groups on the sol-gel surface can provide negative countercharges. The catalytic performance of $\mathrm{CPO}$ sol-gel beads dropped from $12.6 \pm 3 \%$ with the substrate pyrogallol to $9 \pm$ $0.4 \%$ with the substrate ABTS relative to the corresponding assay with free $\mathrm{CPO}$ in solution. The CPO sol-gel beads adopted the green color of the ABTS peroxidation product. Kadnikova and coworkers observed the formation of several side products for the peroxidation reaction of ABTS by horseradish peroxidase in a sol-gel matrix [38]. The peroxidation reaction with ABTS and possibly other substrates, including pyrogallol, might therefore be more complex than in solution.

We further observed that preequilibration of $\mathrm{CPO}$ sol-gel beads with pyrogallol considerably improved catalytic performance. For example, preequilibration with $72 \mathrm{mM}$ pyrogallol for 3 hours in comparison to using $35 \mathrm{mM}$ pyrogallol without preequilibration increased the relative activity from 12.3 to $19.6 \%$. The strategy to preequilibrate enzyme sol-gel materials with an excess of substrate before adding a cosubstrate was already successfully applied by Smith and coworkers [23] in their study on sol-gel encapsulated horseradish peroxidase. Based on the data presented in Figure 1(a), however, we would not expect an increase in catalytic performance for sol-gel entrapped CPO as the pyrogallol concentration is raised from 35 to $72 \mathrm{mM}$. In fact, substrate inhibition should slightly lower the activity of CPO. Adsorption of pyrogallol molecules to the sol-gel surface or physical entrapment could further enhance the local effective concentration of pyrogallol around the enzyme. One key difference between the experiment leading to Figure 1(a) and the preequilibration experiment is the timing of adding the cosubstrate $\mathrm{H}_{2} \mathrm{O}_{2}$. Manoj et al. [29] argue that substrate inhibition of $\mathrm{CPO}$ is not simply caused by blocking the active site of the enzyme with excess substrate molecules. Instead they propose more complex substrate inhibition mechanisms that involve secondary conversion of an already formed product or competition by transient intermediates leading to alternate products. Both substrate inhibition scenarios require the immediate presence of the cosubstrate $\mathrm{H}_{2} \mathrm{O}_{2}$. 
TABLE 3: Properties of CPO sol-gel beads prepared with different casting buffers.

\begin{tabular}{|c|c|c|c|}
\hline $\mathrm{pH}$ of casting buffer & 4.5 & 5.5 & 6.5 \\
\hline BET surface area $\left(\mathrm{m}^{2} / \mathrm{g}\right)$ & $710 \pm 40^{*}$ & $740 \pm 60$ & $470 \pm 40$ \\
\hline Total pore volume $\left(\mathrm{cm}^{3} / \mathrm{g}\right)$ & $0.58 \pm 0.02$ & $0.60 \pm 0.06$ & $0.32 \pm 0.04$ \\
\hline Average pore diameter (nm) & $3.3 \pm 0.3$ & $3.2 \pm 0.1$ & $2.7 \pm 0.1$ \\
\hline Activity (mIU) & $251 \pm 2$ & $242 \pm 29$ & $161 \pm 13$ \\
\hline Specific activity (IU/mg) & $157 \pm 1$ & $151 \pm 18$ & $100 \pm 8$ \\
\hline Activity compared to free CPO (\%) & 18 & 17 & 11 \\
\hline${\text { Cumulative leakage }(\%)^{\dagger}}^{\dagger}$ & 13 & 14 & 9 \\
\hline
\end{tabular}

3.7. Modification of Sol-Gel Procedure Using MTMS. To modify the surface of the sol-gel material, we incorporated MTMS at molar ratios of 5, 20, and $40 \%$ in the sol solution. The addition of MTMS will introduce nonpolar methyl groups rendering the surface of the silica nanostructure more hydrophobic [39]. The casting buffer had a $\mathrm{pH}$ value of 6.0 and the total CPO loading was $4 \mu \mathrm{g} / \mathrm{mL}$. The addition of MTMS resulted in longer gelation times, for example, up to 240 minutes for a molar ratio of $40 \%$ MTMS. Unfortunately, the beads prepared with MTMS were more brittle and fragile than any of the other CPO sol-gel beads prepared in this study. The brittleness of the beads rendered their handling more challenging. Regardless of the amount of incorporated MTMS, the activity was approximately $14 \pm 1 \%$ compared to a solution reference assay. The cumulative leakage often exceeded $20 \%$. We cannot rule out that the physical instability of the beads during and after a buffer exchange might have contributed to higher apparent leakage and higher apparent activity values. In contrast to other enzymes, notably lipase, which showed interfacial activation and performed better inside more hydrophobic nanostructures [40], the incorporation of MTMS into the CPO sol-gel material did not improve catalytic performance in a systematic manner.

3.8. Modification of Sol-Gel Procedure Using More Acidic Casting Buffers. The enzyme CPO is stable under acidic conditions [24]. We exploited this CPO specific property and prepared CPO sol-gel beads using casting buffers with $\mathrm{pH}$ values of $4.5,5.5$, and 6.5. All sample preparations were conducted in parallel with the same batches of CPO, TMOS, and buffer reagents. The gelation time increased with more acidic casting buffers, but the sol-gel beads remained easy to handle and transparent. The CPO loading was $4 \mu \mathrm{g} / \mathrm{mL}$. All CPO solgel preparations were divided into two portions. One portion was used for porosimetry studies and the other portion was used for leakage and activity measurements (see Table 3). The properties of CPO sol-gel beads cast at $\mathrm{pH} 4.5$ and 5.5 are virtually identical, but the CPO sol-gel beads cast at $\mathrm{pH}$ 6.5 show significantly lower values in all categories. This indicates a change in the matrix formation of the sol-gel as the casting $\mathrm{pH}$ drops to or below $\mathrm{pH}$ 5.5. Overall, the porosimetry data is positively correlated with catalytic performance and, unfortunately, leakage. All three porosimetric properties, including larger average pore size, BET surface area, and pore

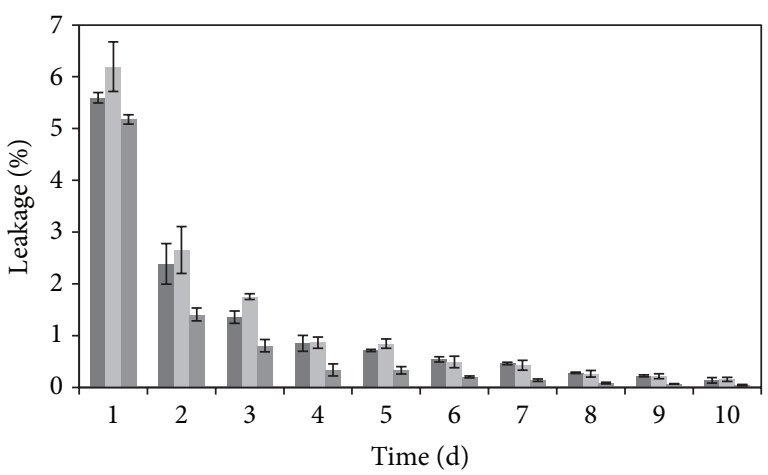

FIGURE 8: The storage buffer of CPO sol-gel beads prepared with casting buffers at $\mathrm{pH} 4.5$ (dark grey bars), 5.5 (grey bars), and 6.5 (light grey bars) was exchanged on a daily basis and monitored for $\mathrm{CPO}$ activity. All samples were prepared in triplicate with eight CPO sol-gel beads per sample tube. The bar height represents the mean value and the error bar \pm one standard deviation.

volume, indicate reduced steric hindrance for material transport inside the sol-gel nanostructure. As a consequence, catalytic performance increased. Smaller average pore sizes, on the other hand, can aid in the retention of CPO.

The dimensions of the protein CPO are $5.3 \mathrm{~nm} \times 4.6 \mathrm{~nm}$ $\times 6.0 \mathrm{~nm}$ [19]. The average pore diameters of approximately $3 \mathrm{~nm}$ are only slightly smaller than the size of CPO. Nevertheless, CPO remained well entrapped after completion of the sol-gel maturation phase. Attractive electrostatic forces did not most likely aid in the retention of CPO as the storage buffer had a $\mathrm{pH}$ value of 4.2 which is close to the isoelectric point of CPO. The isoelectric point of CPO from C. fumago was calculated to be approximately $4.0[18,21]$. Isoelectric focusing experiments on CPO from Pseudomonas pyrrocinia yielded an isoelectric point of 4.1 [41]. For all buffer conditions employed in our study, the net charge on the surface of CPO is therefore either close to zero or negative.

Our observation that more acidic casting buffers result in greater porosimetry of sol-gels agrees well with several previous studies [42, 43]. However, not all enzymes will respond well to the use of more acidic casting conditions. Notably, enzymes have different $\mathrm{pH}$ profiles and some enzymes are inactive under acidic conditions. Sol-gel entrapped cholinesterase, for example, showed better performance 
in silica nanostructures prepared at $\mathrm{pH}$ values of 7.0 and 8.0 and then $6.0[44]$.

\section{Conclusion}

The enzyme CPO was successfully entrapped inside a silica nanostructure prepared from the precursor TMOS with or without addition of the hydrophobic modifier MTMS. Since $\mathrm{CPO}$ is stabile in acidic buffers, we further modified the solgel procedure by using casting buffers with $\mathrm{pH}$ values of 4.5 , $5.5,6.0$, and 6.5. The catalytic performance of optimized CPO sol-gel beads approached $18 \%$ relative to free $\mathrm{CPO}$ in solution as assessed via the pyrogallol peroxidation assay. A combination of factors, such as enzyme leakage from the sol-gel host, insufficient recovery from inactivation caused by initial methanol exposure, hindered product release, or alternate reaction pathways, are most likely responsible for the decline in catalytic performance of $\mathrm{CPO}$ after sol-gel entrapment. The use of more acidic casting buffers in the sol-gel procedure provided the most leverage for optimization by yielding more porous silica nanostructures. Overall, our findings are of importance for the optimization of other sol-gel materials devised for applications in biosensing or biocatalysis or designed for the controlled release of bioactive compounds.

\section{Conflict of Interests}

The authors declare that there is no conflict of interests regarding the publication of this paper.

\section{Acknowledgments}

Funding for this project was obtained from the Research Corporation for Science Advancement (Cottrell College Science Award to Monika Sommerhalter) and California State University East Bay (Faculty and Student Research Grants to Monika Sommerhalter, Selina Chan, and Tuan Le and a Sieber-Tombari award to Monika Sommerhalter). Professor Daryl Eggers, San Jose State University, kindly invited the authors to perform the $\mathrm{CD}$ measurements in his laboratory. The authors are also grateful to Professor Ann McPartland for providing detailed feedback on their paper.

\section{References}

[1] B. C. Dave, B. Dunn, J. S. Valentine, and J. I. Zink, "Nanoconfined proteins and enzymes: sol-gel-based biomolecular materials," Nanotechnology, ACS Symposium Series, vol. 622, pp. 351365,1996

[2] I. Gill and A. Ballesteros, "Bioencapsulation within synthetic polymers (part 1): sol-gel encapsulated biologicals," Trends in Biotechnology, vol. 18, no. 7, pp. 282-296, 2000.

[3] D. Avnir, T. Coradin, O. Lev, and J. Livage, "Recent bioapplications of sol-gel materials," Journal of Materials Chemistry, vol. 16, no. 11, pp. 1013-1030, 2006.

[4] D. R. Morris and L. P. Hager, "Chloroperoxidase. I. Isolation and properties of the crystalline glycoprotein," The Journal of Biological Chemistry, vol. 241, no. 8, pp. 1763-1768, 1966.
[5] V. Yazbik and M. Ansorge-Schumacher, "Fast and efficient purification of chloroperoxidase from C. fumago," Process Biochemistry, vol. 45, no. 2, pp. 279-283, 2010.

[6] M. Hofrichter and R. Ullrich, "Heme-thiolate haloperoxidases: versatile biocatalysts with biotechnological and environmental significance," Applied Microbiology and Biotechnology, vol. 71, no. 3, pp. 276-288, 2006.

[7] V. M. Dembitsky, "Oxidation, epoxidation and sulfoxidation reactions catalysed by haloperoxidases," Tetrahedron, vol. 59, no. 26, pp. 4701-4720, 2003.

[8] L. Santhanam and J. S. Dordick, "Chloroperoxidase catalyzed epoxidation of styrene in aqueous and non-aqueous media," Biocatalysis and Biotransformation, vol. 20, no. 4, pp. 265-274, 2002.

[9] M. Ayala, N. R. Robledo, A. Lopez-Munguia, and R. VazquezDuhalt, "Substrate specificity and ionization potential in chloroperoxidase-catalyzed oxidation of diesel fuel," Environmental Science and Technology, vol. 34, no. 13, pp. 2804-2809, 2000.

[10] R. Vázquez-Duhalt, M. Ayala, and F. J. Márquez-Rocha, "Biocatalytic chlorination of aromatic hydrocarbons by chloroperoxidase of Caldariomyces fumago," Phytochemistry, vol. 58, no. 6, pp. 929-933, 2001.

[11] E. Terrés, M. Montiel, S. Le Borgne, and E. Torres, "Immobilization of chloroperoxidase on mesoporous materials for the oxidation of 4,6-dimethyldibenzothiophene, a recalcitrant organic sulfur compound present in petroleum fractions," Biotechnology Letters, vol. 30, no. 1, pp. 173-179, 2008.

[12] V. Trevisan, M. Signoretto, S. Colonna, V. Pironti, and G. Strukul, "Microencapsulated chloroperoxidase as a recyclable catalyst for the enantioselective oxidation of sulfides with hydrogen peroxide," Angewandte Chemie International Edition, vol. 43, no. 31, pp. 4097-4099, 2004.

[13] N. Spreti, R. Germani, A. Incani, and G. Savelli, "Stabilization of chloroperoxidase by polyethylene glycols in aqueous media: kinetic studies and synthetic applications," Biotechnology Progress, vol. 20, no. 1, pp. 96-101, 2004.

[14] J.-B. Park and D. S. Clark, "New reaction system for hydrocarbon oxidation by chloroperoxidase," Biotechnology and Bioengineering, vol. 94, no. 1, pp. 189-192, 2006.

[15] J.-Z. Liu and M. Wang, "Improvement of activity and stability of chloroperoxidase by chemical modification," BMC Biotechnology, vol. 7, no. 1, article 23, 2007.

[16] L. Zhi, Y. Jiang, Y. Wang, M. Hu, S. Li, and Y. Ma, "Effects of additives on the thermostability of chloroperoxidase," Biotechnology Progress, vol. 23, no. 3, pp. 729-733, 2007.

[17] T. A. Kadima and M. A. Pickard, "Immobilization of chloroperoxidase on aminopropyl-glass," Applied and Environmental Microbiology, vol. 56, no. 11, pp. 3473-3477, 1990.

[18] Y.-J. Han, J. T. Watson, G. D. Stucky, and A. Butler, "Catalytic activity of mesoporous silicate-immobilized chloroperoxidase," Journal of Molecular Catalysis B: Enzymatic, vol. 17, no. 1, pp. 1-8, 2002.

[19] J. Aburto, M. Ayala, I. Bustos-Jaimes et al., "Stability and catalytic properties of chloroperoxidase immobilized on SBA-16 mesoporous materials," Microporous and Mesoporous Materials, vol. 83, no. 1-3, pp. 193-200, 2005.

[20] M. Hartmann and C. Streb, "Selective oxidation of indole by chloroperoxidase immobilized on the mesoporous molecular sieve SBA-15," Journal of Porous Materials, vol. 13, no. 3-4, pp. 347-352, 2006. 
[21] S. Hudson, J. Cooney, B. K. Hodnett, and E. Magner, "Chloroperoxidase on periodic mesoporous organosilanes: immobilization and reuse," Chemistry of Materials, vol. 19, no. 8, pp. 2049 2055, 2007.

[22] R. A. Sheldon, "Enzyme immobilization: the quest for optimum performance," Advanced Synthesis \& Catalysis, vol. 349, no. 8-9, pp. 1289-1307, 2007.

[23] K. Smith, N. J. Silvernail, K. R. Rodgers, T. E. Elgren, M. Castro, and R. M. Parker, "Sol-gel encapsulated horseradish peroxidase: a catalytic material for peroxidation," Journal of the American Chemical Society, vol. 124, no. 16, pp. 4247-4252, 2002.

[24] K. M. Manoj and L. P. Hager, "Chloroperoxidase, a janus enzyme," Biochemistry, vol. 47, no. 9, pp. 2997-3003, 2008.

[25] V. M. Samokyszyn and P. R. Ortiz de Montellano, "Topology of the chloroperoxidase active site: regiospecificity of heme modification by phenylhydrazine and sodium azide," Biochemistry, vol. 30, no. 50, pp. 11646-11653, 1991.

[26] M. M. Bradford, "A rapid and sensitive method for the quantitation of microgram quantities of protein utilizing the principle of protein-dye binding," Analytical Biochemistry, vol. 72, no. 1-2, pp. 248-254, 1976.

[27] D. K. Eggers and J. S. Valentine, "Molecular confinement influences protein structure and enhances thermal protein stability," Protein Science, vol. 10, no. 2, pp. 250-261, 2001.

[28] J. H. Harreld, T. Ebina, N. Tsubo, and G. Stucky, "Manipulation of pore size distributions in silica and ormosil gels dried under ambient pressure conditions," Journal of Non-Crystalline Solids, vol. 298, no. 2-3, pp. 241-251, 2002.

[29] K. M. Manoj, A. Baburaj, B. Ephraim et al., "Explaining the atypical reaction profiles of heme enzymes with a novel mechanistic hypothesis and kinetic treatment," PLoS ONE, vol. 5, no. 5, Article ID e10601, 2010.

[30] D. Jung and M. Hartmann, "Oxidation of indole with CPO and GOx immobilized on mesoporous molecular sieves," Catalysis Today, vol. 157, no. 1-4, pp. 378-383, 2010.

[31] M. L. Ferrer, F. del Monte, and D. Levy, "A novel and simple alcohol-free sol-gel route for encapsulation of labile proteins," Chemistry of Materials, vol. 14, no. 9, pp. 3619-3621, 2002.

[32] M. Sundaramoorthy, J. Terner, and T. L. Poulos, “The crystal structure of chloroperoxidase: a heme peroxidase-cytochrome P450 functional hybrid," Structure, vol. 3, no. 12, pp. 1367-1377, 1995.

[33] X. W. Yi, A. Conesa, P. J. Punt, and L. P. Hager, "Examining the role of glutamic acid 183 in chloroperoxidase catalysis," Journal of Biological Chemistry, vol. 278, no. 16, pp. 13855-13859, 2003.

[34] S. R. Blanke, S. A. Martinis, S. G. Sligar, L. P. Hager, J. J. Rux, and J. H. Dawson, "Probing the heme iron coordination structure of alkaline chloroperoxidase," Biochemistry, vol. 35, no. 46, pp. 14537-14543, 1996.

[35] B. Dunn and J. I. Zink, "Probes of pore environment and molecule-matrix interactions in sol-gel materials," Chemistry of Materials, vol. 9, no. 11, pp. 2280-2291, 1997.

[36] W. A. Loughlin and D. B. Hawkes, "Effect of organic solvents on a chloroperoxidase biotransformation," Bioresource Technology, vol. 71, no. 2, pp. 167-172, 2000.

[37] E. Kiljunen and L. T. Kanerva, "Chloroperoxidase-catalysed oxidation of alcohols to aldehydes," Journal of Molecular Catalysis B: Enzymatic, vol. 9, no. 4-6, pp. 163-172, 2000.

[38] E. N. Kadnikova and N. M. Kostić, "Oxidation of ABTS by hydrogen peroxide catalyzed by horseradish peroxidase encapsulated into sol-gel glass. Effects of glass matrix on reactivity,"
Journal of Molecular Catalysis B: Enzymatic, vol. 18, no. 1-3, pp. 39-48, 2002.

[39] A. Venkateswara Rao and D. Haranath, "Effect of methyltrimethoxysilane as a synthesis component on the hydrophobicity and some physical properties of silica aerogels," Microporous and Mesoporous Materials, vol. 30, no. 2-3, pp. 267-273, 1999.

[40] M. T. Reetz, A. Zonta, and J. Simpelkamp, "Efficient immobilization of lipases by entrapment in hydrophobic sol-gel materials," Biotechnology and Bioengineering, vol. 49, no. 5, pp. 527-534, 1996.

[41] W. Wiesner, K.-H. van Pee, and F. Lingens, "Purification and characterization of a novel bacterial non-heme chloroperoxidase from Pseudomonas pyrrocinia," Journal of Biological Chemistry, vol. 263, no. 27, pp. 13725-13732, 1988.

[42] Y. Xi, Z. Liangying, and W. Sasa, "Pore size and pore-size distribution control of porous silica," Sensors and Actuators: B. Chemical, vol. 25, no. 1-3, pp. 347-352, 1995.

[43] C. Lin and J. A. Ritter, "Effect of synthesis pH on the structure of carbon xerogels," Carbon, vol. 35, no. 9, pp. 1271-1278, 1997.

[44] M. Altstein, G. Segev, N. Aharonson, O. Ben-Aziz, A. Turniansky, and D. Avnir, "Sol-gel entrapped cholinesterases: a microtiter plate method for monitoring anti-cholinesterase compounds," Journal of Agricultural and Food Chemistry, vol. 46, no. 8, pp. 3318-3324, 1998. 

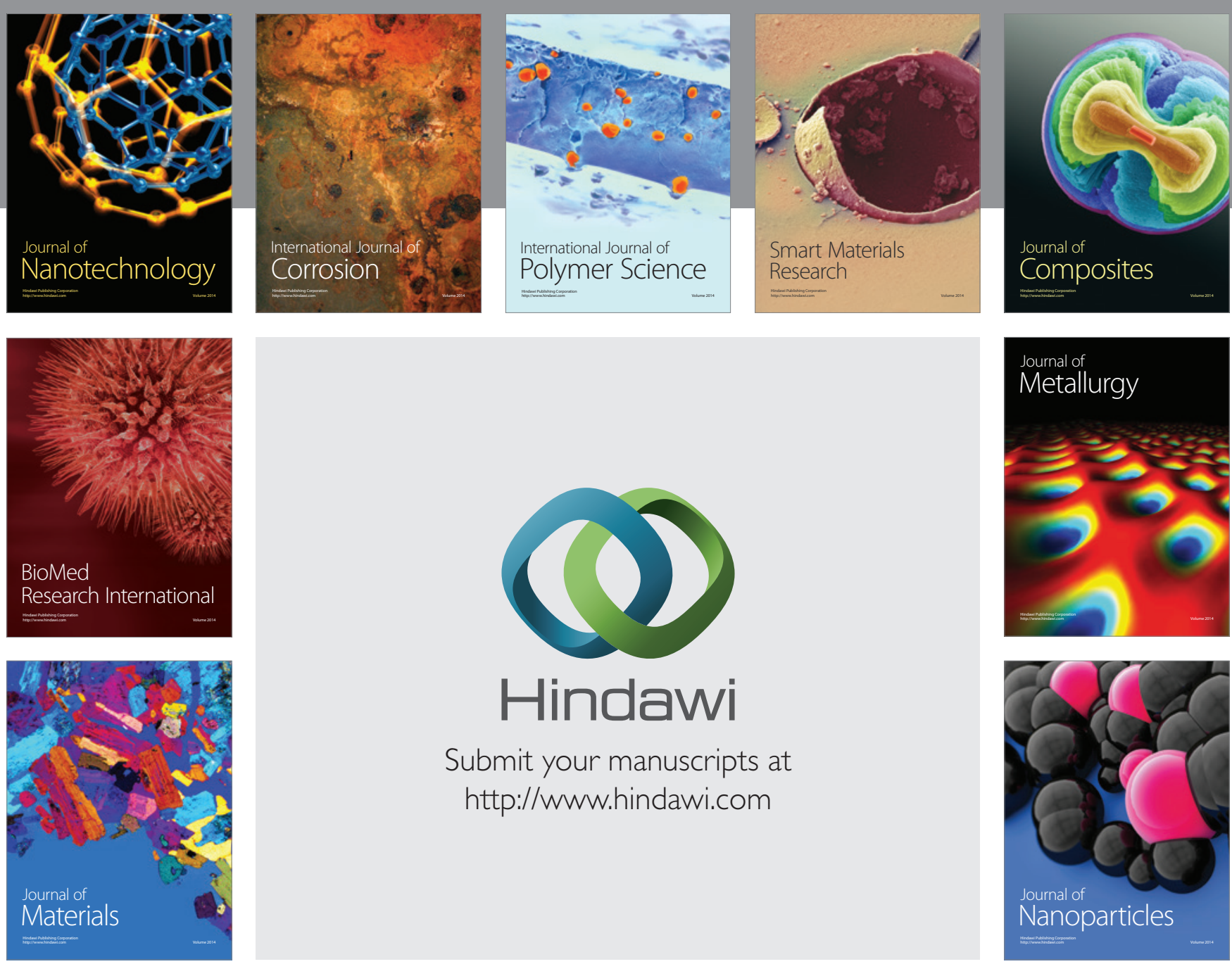

Submit your manuscripts at http://www.hindawi.com
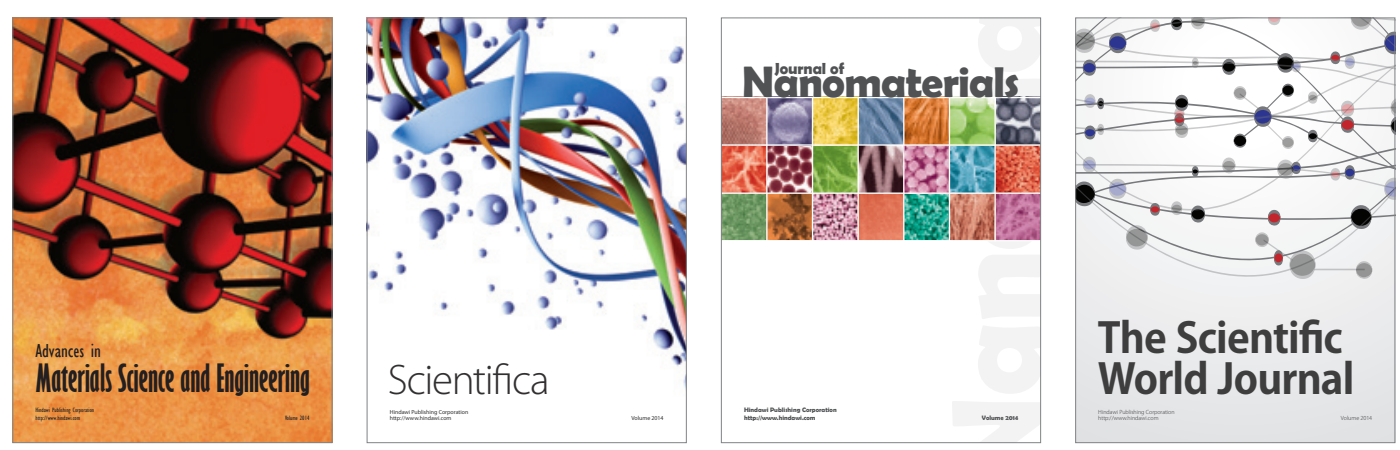

\section{The Scientific World Journal}
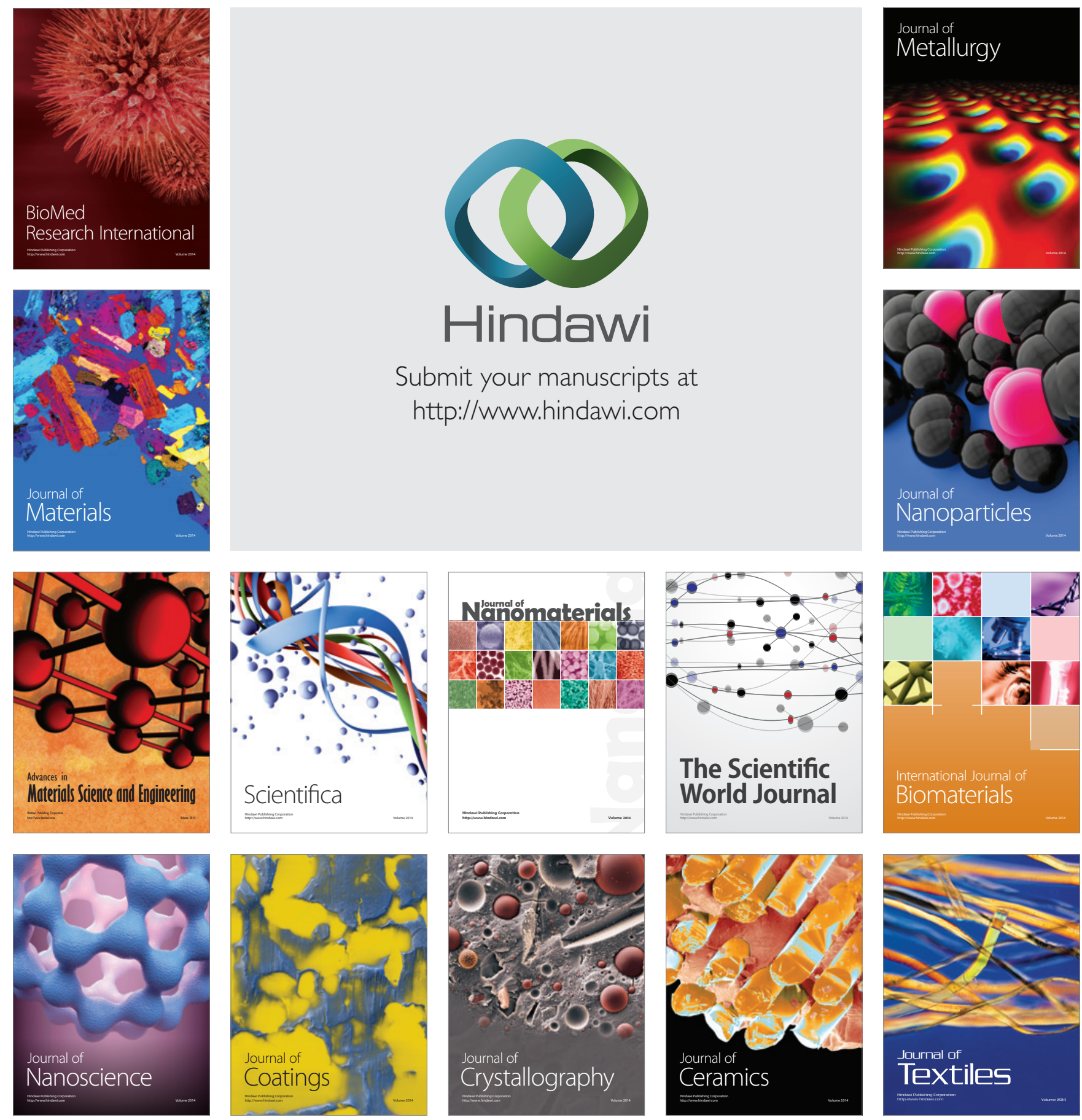